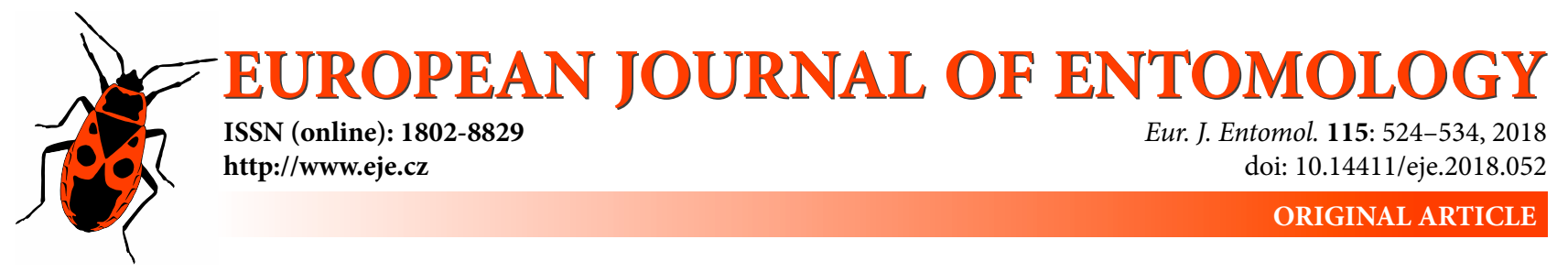

\title{
A three year study of the phenology of insect larvae (Coleoptera, Diptera) in water-filled tree holes in the canopy of a beech tree
}

\author{
MARTIN M. GOSSNER \\ Forest Entomology, Swiss Federal Research Institute WSL, Zürcherstrasse 111, CH-8903 Birmensdorf, Switzerland, \\ e-mail: martin.gossner@wsl.ch
}

Key words. Coleoptera, Diptera, phytotelmata, phenology, aquatic habitat, beech forest, community composition, stratification

\begin{abstract}
Water-filled tree holes are abundant microhabitats in forests worldwide and are inhabited by specialized communities of invertebrates. Despite their importance, the temporal dynamics of communities within and between years are largely unknown. Here, I present a case study on the phenology of insect larvae in two holes in a beech tree (lower and upper canopy) located in southern Germany over a period of three years. I asked whether water temperature and the characteristics of insect larvae at the community and population levels are similar in periodicity every year and whether they differ in the lower and upper canopy. The water temperature in tree holes differed greatly from air temperature, and this effect was more pronounced in the lower than in the upper canopy, which resulted in a lower probability of drying out occurring in the lower canopy. This was associated with a higher species richness in the lower canopy and greater abundance of drought tolerant species in the upper canopy. There was a significant periodicity in larval abundance, biomass, species richness and body size distribution of abundant species in both tree holes, but it was not seasonal. This result indicates that unpredictable drying out of tree holes are more important drivers of tree hole community dynamics than changes in water temperature. The community of larvae in the tree hole in the upper canopy lagged behind that in the lower canopy, which indicates that most species mainly colonize the more stable microhabitats in the lower canopy. Hopefully this case study will encourage future larger-scale phenological studies to test (1) whether the patterns observed in this study can be generalized over larger spatial scales and (2) the relative importance of abiotic and biotic drivers of the dynamics of communities in tree holes.
\end{abstract}

\section{INTRODUCTION}

Ephemeral water bodies associated with living plants occur worldwide and are inhabited by a high diversity of organisms, from bacteria and protists to invertebrates and vertebrates (Kitching, 2000). Among these microhabitats, the exceptionally diverse tropical phytotelmata in green plant parts, such as leaf axils of tank bromeliads, are the most well-known (Srivastava et al., 2004, 2008; Yanoviak et al., 2006; Petermann et al., 2015). However, water-filled tree holes, called dendrotelmata, also provide microhabitats for numerous species (Kitching, 1971; Yanoviak, 2001; Schmidl et al., 2008; Gossner et al., 2016). They occur ubiquitously in temperate and tropical forests and may therefore, together with phytotelmata, represent the most abundant freshwater aquatic ecosystem worldwide (Carpenter, 1982).

In temperate forests, water-filled tree holes, comprising rot-holes and pans, occur with varying frequency. In rot-holes, which form in holes in stems, branch breaks and stumps, water has contact with the wood. In pans, which are created by stem and branch forks as well as between buttress roots, the hole is lined with bark (Kitching, 1971). Both types of water-filled tree holes occur in a many broad- leaved and coniferous species (Rohnert, 1951; Schmidl et al., 2008; Rotheray, 2013; Gossner et al., 2016), but the frequency of such structures varies between different species of trees. In Central Europe, European beech (Fagus sylvatica L.) is the tree species in which such water-filled tree holes occur most frequently, most likely because of its root and branch architecture and its high abundance (Rohnert, 1951). Water-filled tree holes occur between buttress roots up to a height of over $30 \mathrm{~m}$ in the canopy, where they can be found in stem and branch forks and holes formed when a branch breaks (Gossner et al., 2016). They fill with rain water, either directly or by stem flow. Through this process, nutrients are transferred from foliage and bark into the tree holes, and thus the chemical content of the water depends not only on the species of tree, but also on dry atmospheric depositions on the bark (Carlisle et al., 1966; Eaton et al., 1973; Paradise \& Dunson, 1998). The main source of energy for the saprophagous communities in these tree holes is leaf litter, which also varies in quality between different species of trees (Fish \& Carpenter, 1982; Carpenter, 1983), supplemented mainly by dead arthropods (Yee \& Juliano, 2006). The varying nutritional conditions among tree holes affect the reproduction of individual species of 
invertebrates (Mercer, 1993), as well as the composition of invertebrates inhabiting holes in particular species of trees (Rohnert, 1951).

Early studies mainly describe the ecology of water-filled tree holes and the species that inhabit them (Varga, 1928; Theinemann, 1934; Rohnert, 1951; Kitching, 1971). Most later studies in Central Europe have involved sampling tree holes at only one point in time and have addressed topics such as the preference of insect species for a particular water chemistry (Schmidl et al., 2008), microhabitat (Rotheray, 2013) or forest management (Gossner et al., 2016; Petermann et al., 2016). Studies on the temporal dynamics of species inhabiting water-filled tree holes have mostly focused on selected species or species groups over one or more annual cycles, e.g. a few species of mosquito (Sinsko \& Craig, 1979; Bradshaw \& Holzapfel, 1984), Syrphidae (Rotheray, 2013; Rotheray et al., 2016), a Ceratopogonid (Kitching, 1972b), or a Chironomid (Kitching, 1972a), or are anecdotal (von Brandt, 1934; Rohnert, 1951). Studies on the phenology of whole communities in water-filled tree holes are rare and mostly restricted to subtropical rain forests (Kitching, 1983, 1987; Kitching \& Beaver, 1990) or to artificial tree holes (Ptatscheck \& Traunspurger, 2015). The limited number of quantitative studies focusing on temporal population dynamics of whole insect communities in water-filled tree holes in temperate forests are mostly restricted to one entire season (Kitching, 1971; Woodward et al., 1988; Green, 1990; Barrera, 1996; Devetter, 2004; Paradise, 2004) or to an even shorter period (Sota, 1996). I am aware of only two studies, conducted at the same location in North America, that considered a period of more than one year (Paradise et al., 2008; Smith et al., 2009). Thus, it is unclear whether the communities in European waterfilled tree holes exhibit a clear seasonal periodicity or vary in their occurrence between years. Because tree holes are highly variable in their physical and chemical characteristics (Gossner et al., 2016), it is difficult to compare different tree holes that are sampled at different times (space for time substitutions). However, sampling the same tree hole over time without considerably influencing the organisms that inhabit them is a great challenge.

Here, I studied the temperature and the communities of insects in two tree holes at different heights in the canopy of a beech tree over a period of three years by subsampling. I determined whether water temperature and the characteristics of insect larvae at the community and population levels are similar between years and whether they differ in the lower and upper canopy. With this investigation I aimed to test the suitability of taking small water samples for studying the temporal dynamics of insect larvae in tree holes and pose further questions about the temporal dynamics of insect communities developing in water-filled tree holes that should be addressed at larger spatial scales in the future.

\section{MATERIALS AND METHODS}

\section{Study site and tree}

Monitoring of temperature and occurrence of insect larvae was done over a period of three years in an old broad-leaved forest
("Schlemmerholz") near Freising, Germany. This forest is part of the "Oberbayerisches Tertiärhügelland" at an altitude of $480 \mathrm{~m}$ a.s.l. Under natural conditions, the region would be dominated by colline to high montane beech forest (Fagus sylvatica L.). Owing to management for economic reasons, however, this forest is now dominated by spruce (Picea abies L.), and broad-leaved forests are restricted to small patches. The mean annual precipitation is $750-800 \mathrm{~mm}$ and the mean annual temperature is $7-8^{\circ} \mathrm{C}$.

The broad-leaved forest studied is multi-layered, 1 ha in size and dominated by European beech ( F. sylvatica) and pedunculate oak (Quercus robur L.) (Fig. S1-1). In addition, there are low proportions of other broad-leaved species of trees (Acer pseudoplatanus L., A. platanoides L., Ulmus glabra Huds., Fraxinus excelsior L., Carpinus betulus L.) and conifers [P. abies, Pinus sylvestris L., Pseudotsuga menziesii (Mirbel) Franco]. Twenty four tree holes per hectare were recorded in the area of forest studied (mapped on 15 June 2017), which is an average value when compared with counts recorded in a large-scale study of tree holes in beech forests in two regions of Germany (Fig. S1-2) (Gossner et al., 2016).

The beech tree studied $\left(48.40^{\circ} \mathrm{N}, 11.71^{\circ} \mathrm{E}\right)$ had a diameter of 75 $\mathrm{cm}$ and a height of $35 \mathrm{~m}$ (Fig. S1-1). Two water-filled holes at the bases of branches at two different heights $(10.2 \mathrm{~m}, 20.2 \mathrm{~m})$ were studied over a period of almost three years.

\section{Abiotic variables}

The maximum volume of the tree holes was measured by removing all the water and detritus from the holes and filling them completely with rainwater one year after the end of the study, on 15 June 2017.

Temperature in the tree holes was measured using high-resolution Thermochron ${ }^{\circledR}$ iButtons ${ }^{\circledR}$ DS1921Z-F5 in water-proof protective capsules DS9107 (Fig. S1-1). The temporal resolution of measurements was one hour. Loggers were installed on 17 October 2013 and data were retrieved on average once every two months. The last measurement was recorded on 25 May 2016 because the batteries failed during the following sampling interval.

Data on air temperature at $2 \mathrm{~m}$ above the ground and precipitation were taken from a nearby weather station of the Bavarian State Research Center for Agriculture (Freising BAM008, $48.41^{\circ} \mathrm{N}, 11.72^{\circ} \mathrm{E}, 470 \mathrm{~m}$ a.s.l., distance to the tree studied ca. $700 \mathrm{~m}$ ). Data at $1 \mathrm{~h}$ intervals were obtained from the online database. The absolute difference between water temperature in the tree holes and air temperature was calculated at $1 \mathrm{~h}$ intervals.

\section{Sampling and morphometric measurements of insect larvae}

It is difficult to sample insect larvae to gather reliable data on temporal patterns over time without affecting the communities. A water sample of $15 \mathrm{ml}$ was taken from both holes approximately once every two months. This volume is $10 \%$ of the median volume recorded in June in holes with a maximum volume of $>100$ $\mathrm{ml}$ in the canopy of beech trees (Gossner et al., 2016). This small sample volume was used to minimize disturbance of the system. Samples were only collected when tree holes were either completely or almost completely full of water in order to avoid the error that would result from sampling a greater concentration of larvae in a smaller volume of water. Prior to sampling, the water in the tree holes was first stirred to homogenize the distribution of larvae and then sampled with a syringe $(5 \mathrm{~mm}$ diameter opening allowed the sampling of large larvae such as those of Myathropa florea). Each sample was transferred to a Falcon tube and cooled before the larvae were processed in the laboratory.

An additional $15 \mathrm{ml}$ sample of water was taken on 15 June 2017 , followed by a complete harvesting of the tree hole contents 
to determine whether the earlier samples reflected the community composition of the entire tree hole. The contents of the tree holes were processed in the following ways: (1) the detritus was flushed through sieves of different mesh sizes and finally through filter paper; (2) all detritus retained by the sieves with a mesh size $\geq 0.5$ $\mathrm{mm}$ was classed as coarse debris, and the remaining fractions as fine debris; (3) all fractions were searched for insect larvae, which were subsequently transferred to vials containing $70 \%$ ethanol and stored at $5^{\circ} \mathrm{C}$ until further processing. The detritus was dried in a drying oven for $24 \mathrm{~h}$ at $70^{\circ} \mathrm{C}$ and then weighed.

Insect larvae were identified to family using the following identification keys for common insect larvae (Stehr, 1987; Nilsson, 1996; Stresemann et al., 2005). For genus and species identification of Diptera, Pankratova (1970), Cranston (1982) and Lindegaard (1997) were used for Chironomidae, Nilsson (1997) for Ceratopogonidae, Utrio (1976), Cranston \& Judd (1987) and Mohrig (1969) for Culicidae, Rozkošný \& Gregor (2004) for Muscidae, Dixon (1960), Hartley (1961) and Rotheray (1993) for Syrphidae, Nilsson (1997) for Psychodidae and Nilsson (1997) for Tipulidae. For species identification of Coleoptera, family Scirtidae, the key of Klausnitzer (1996) was used.

The body lengths and widths, and width of the head capsules (when present) of all the larvae in the $15 \mathrm{ml}$ samples were measured using a measuring eyepiece. The body length of each larva in the additional sample collected in 2017 was measured using a Leica DVM6 Digital microscope at WSL.

Biomass was calculated as dry weight based on body length and order-specific constants given in Smock (1980):

$\ln \mathrm{W}=\ln \mathrm{a}+\mathrm{b} * \ln \mathrm{L}$

where $\mathrm{W}=$ dry weight, and $\mathrm{a}, \mathrm{b}=$ regression constants obtained from regressions of dry weight as a function of body length.

\section{Data analyses}

All analyses were done using $\mathrm{R}$ version 3.2.4. Time series analyses were conducted to compare the lower and upper tree holes throughout the three years sampled in terms of (1) the mean hourly water temperature, (2) the absolute difference between tree hole water temperature and air temperature, (3) community parameters: (a) total number of individuals, (b) biomass, (c) species richness per $15 \mathrm{ml}$ sample, and (4) the number of individuals and mean larval body length per $15 \mathrm{ml}$ sample of the two most abundant species.

For analyzing periodicity, partial autocorrelations of each time series (lower hole, upper hole) were done separately and crosscorrelations between the two series were calculated using the acf function in R (see Venables \& Ripley, 2002). The partial correlation coefficients were estimated by fitting autoregressive models of successively higher orders. The lag was plotted in units of time, not in number of observations.

\section{RESULTS}

The lower tree hole (exposure SE, depth $28 \mathrm{~cm}$, length $25 \mathrm{~cm}$, width $14 \mathrm{~cm}$, volume $2600 \mathrm{ml}$ ) was larger than the upper hole (exposure SW, depth $18 \mathrm{~cm}$, length $30 \mathrm{~cm}$, width $13 \mathrm{~cm}$, volume $1300 \mathrm{ml}$ ). The weight of detritus was $165.85 \mathrm{~g}$ (coarse debris $81.94 \mathrm{~g}$, fine debris $83.91 \mathrm{~g}$ ) in the lower and $37.83 \mathrm{~g}(22.94 \mathrm{~g}, 14.90 \mathrm{~g})$ in the upper hole.

\section{Temperature and precipitation}

Air temperature was between -13.7 and $34.6^{\circ} \mathrm{C}$, and precipitation between 0 and $33.1 \mathrm{~mm}$ per hour throughout the study period. Both variables fluctuated considerably and varied between years, resulting in an acyclic drying out of tree holes (Fig. 1). The water temperature was between -2.25 and $25.38^{\circ} \mathrm{C}$ in the upper and between -2.25 and $24.25^{\circ} \mathrm{C}$ in the lower hole, and differed greatly at the two heights at specific times and seasons. The water temperature in the lower tree hole differed more strongly from air temperature than that in the upper tree hole. This finding is illustrated by the higher peaks temperatures recorded in the upper hole in Fig. 1, and supported by the results of the partial autocorrelation analyses (Table 1, Figs S3-1 to S33 ). This effect was, however, stronger in autumn, winter and spring than in summer (Fig. 2). The upper tree hole dried out six times during the three-year study, and during two of these events not even moist mud remained (see strong peaks in the red line in spring 2015 in Fig. 1; Fig. S4-2). In contrast, the lower tree hole dried out twice and moist mud still remained. Nevertheless, both tree holes froze completely in winter (Fig. 1).

\section{Comparison of samples with the complete harvest}

The harvest of the complete contents of the two holes collected in 2017 contained a total of 372 (lower tree hole) and 163 (upper tree hole) insect larvae. In the $15 \mathrm{ml} \mathrm{sam}$ ples taken before the complete harvest, there were $23(6 \%$ of the complete harvest) and $19(12 \%)$ larvae in the samples from the lower and upper tree holes, respectively. All species that occurred in the tree holes were detected in the samples (Fig. 3). In the complete harvest, the larvae of the most abundant species, Metriocnemus cavicola Kieffer, 1921 (also known as M. martinii Thienemann, 1921) were distinctly smaller in the lower than in the upper tree hole. This was also recorded in the $15 \mathrm{ml}$ sample, but was less pronounced.

\section{Yearly occurrence of the species}

In total, the larvae of at least nine species (not all individuals were identified to species level) of insects were recorded in the two tree holes in this three year study (Fig. 4 \& Supplement S4). More species were recorded in the lower (7) than in the upper hole (6), three occurred exclusively in the lower hole, and two exclusively in the upper hole. The most abundant species were M. cavicola and Prionocyphon serricornis (Mueller, 1821) (Fig. 4). The much higher abundance of $P$. serricornis in the lower hole and the exclusive occurrence of Culicidae [Aedes geniculatus (Olivier, 1791), Anopheles sp.] in the lower hole and of Psychodidae in the upper hole, may indicate a stratification in the occurrence of these species. The raw species data is in Supplement S5.

Shortly after the tree holes filled with water during rainfall following a dry period (Fig. S3-10) and as soon as the ice began to melt in winter, insect larvae were observed. Many live larvae of $P$. serricornis were observed in the water above the ice, indicating that the larvae can survive when the water is completely frozen. In contrast, Myathropa florea sometimes became frozen in the ice and died (Fig. S4-1). In addition, terrestrial insects such as honey bees and beetles used the tree holes as a source of water (Fig. S4-2), especially during dry periods when other sources of water are scarce. In contrast, slugs were 

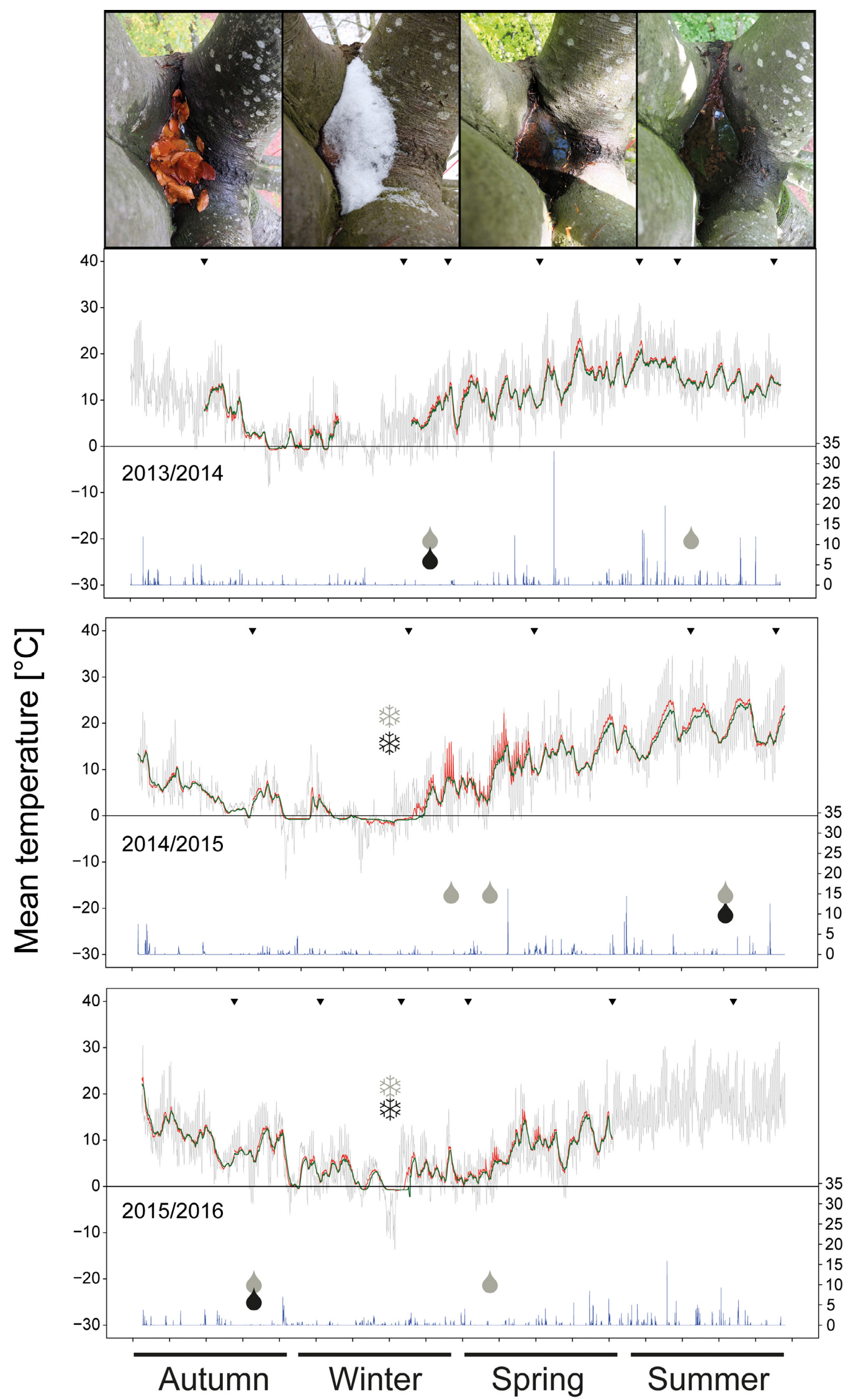

Fig. 1. Mean temperature each hour of the water in tree holes formed where branches fork $10.2 \mathrm{~m}$ (green line) and $20.2 \mathrm{~m}$ (red line) above the ground. The grey line is mean temperature and blue bars precipitation, both measured at a nearby weather station outside the forest. Black triangles indicate dates when samples of water were collected from the tree holes. Water droplet symbols indicate dates when tree holes dried out, and ice crystal symbols indicate dates when the water in the tree holes was completely frozen (black: $10.2 \mathrm{~m}$, grey: 20.2 $\mathrm{m})$. The photographs show the tree hole at $20.2 \mathrm{~m}$ above the ground in the four seasons. 
Table 1. Summary of the results of the partial autocorrelation analyses of the periodicity in the lower and upper tree holes, and of the crosscorrelation between the upper and lower holes. Water temperature and the difference between the water temperature and air temperature, as well as insect communities and populations (only abundant species), were considered. Analyses were done using the autocorrelation function ACF in R (see Venables \& Ripley, 2002). Details of the analyses are shown in Figs S3-2 to S3-10.

\begin{tabular}{|c|c|c|c|}
\hline & Lower hole & Upper hole & Cross-correlation lower vs. upper hole \\
\hline Water temperature & $\begin{array}{l}\text { Significant } \\
\text { periodicity }\end{array}$ & $\begin{array}{l}\text { Significant } \\
\text { periodicity }\end{array}$ & $\begin{array}{l}\text { - positive changes in the upper hole are associated with negative changes } \\
\text { in lower hole and vice versa }\end{array}$ \\
\hline \multicolumn{3}{|c|}{$\begin{array}{l}\rightarrow \text { stronger periodicity } \\
\text { in the upper hole }\end{array}$} & $\rightarrow$ lower hole water temperature lags $b$ \\
\hline
\end{tabular}

\begin{tabular}{lcc}
\hline $\begin{array}{l}\text { Difference between } \\
\text { water temperature } \\
\text { and air temperature }\end{array}$ & $\begin{array}{l}\text { Significant } \\
\text { periodicity }\end{array}$ & $\begin{array}{l}\text { Significant } \\
\text { periodicity }\end{array}$ \\
\hline & $\begin{array}{c}\rightarrow \text { greater buffering against } \\
\text { changes in air temperature } \\
\text { in the lower hole }\end{array}$ \\
\hline
\end{tabular}

\begin{tabular}{|c|c|c|c|}
\hline $\begin{array}{l}\text { Number of insect } \\
\text { larvae }\end{array}$ & $\begin{array}{l}\text { Significant } \\
\text { periodicity }\end{array}$ & $\begin{array}{l}\text { Significant } \\
\text { periodicity }\end{array}$ & $\begin{array}{c}\text { - for smaller time units (lags } 3 \text { and } 4 \text { ), positive changes in the lower hole } \\
\text { are associated with negative changes in the upper hole and vice versa } \\
\text { - for larger time units (lag 7), positive changes in the lower hole are associated } \\
\text { with positive changes in the upper hole }\end{array}$ \\
\hline
\end{tabular}
$\rightarrow$ stronger periodicity
in the upper hole $\quad \rightarrow$ insect abundances in the upper hole lag behind those in the lower hole

\begin{tabular}{|c|c|c|}
\hline $\begin{array}{l}\text { Biomass of insect } \\
\text { larvae }\end{array}$ & $\begin{array}{l}\text { Significant } \\
\text { periodicity }\end{array}$ & $\begin{array}{c}\text { - for small and large time units (lags } 1,2,3 \text { and } 6), \text { positive changes in the lower hole } \\
\text { are associated with positive changes in the upper hole } \\
\text { - for intermediate time units (lag 5), positive changes in the lower hole are associated } \\
\text { with negative changes in the upper hole and vice versa }\end{array}$ \\
\hline
\end{tabular}

\begin{tabular}{|c|c|c|}
\hline & $\begin{array}{l}\rightarrow \text { stronger periodicity } \\
\text { in the upper hole }\end{array}$ & $\rightarrow$ insect biomass values in the upper hole lag behind those in the lower hole \\
\hline \multirow[t]{2}{*}{$\begin{array}{l}\text { Insect larvae species } \\
\text { richness }\end{array}$} & $\begin{array}{l}\text { Significant } \\
\text { periodicity }\end{array}$ & $\begin{array}{c}\text { - for smaller time units (lags } 4 \text { and } 6 \text { ), positive changes in the upper hole } \\
\text { are associated with negative changes in the lower hole and vice versa } \\
\text { - for larger time units (lag 7), positive changes in the lower hole are associated } \\
\text { with positive changes in the upper hole }\end{array}$ \\
\hline & $\begin{array}{l}\rightarrow \text { stronger periodicity } \\
\text { in the upper hole }\end{array}$ & $\rightarrow$ species richness in the upper hole lags behind that in the lower hole \\
\hline \multirow[t]{2}{*}{$\begin{array}{l}\text { Number of individuals } \\
\text { of Metriocnemus } \\
\text { cavicola }\end{array}$} & $\begin{array}{l}\text { Significant } \\
\text { periodicity }\end{array}$ & $\begin{array}{c}\text { - positive changes in the lower hole are associated with negative changes } \\
\text { in the upper hole and vice versa (significant at lags } 3,6 \text { and } 8 \text { ) }\end{array}$ \\
\hline & $\begin{array}{l}\rightarrow \text { stronger periodicity } \\
\text { in the upper hole }\end{array}$ & $\rightarrow$ abundances in the upper hole lag behind those in the lower hole \\
\hline \multirow[t]{2}{*}{$\begin{array}{l}\text { Mean body length } \\
\text { of Metriocnemus } \\
\text { cavicola }\end{array}$} & $\begin{array}{l}\text { Significant } \\
\text { periodicity }\end{array}$ & $\begin{array}{c}\text { - positive changes in the upper hole are associated with positive changes } \\
\text { in the lower hole at lags } 3,5 \text { and } 8 \\
\text { - positive changes in the upper hole are associated with negative changes } \\
\text { in the lower hole and vice versa at lags } 2,7 \text { and } 9\end{array}$ \\
\hline & $\begin{array}{l}\rightarrow \text { stronger periodicity } \\
\text { in the upper hole }\end{array}$ & $\rightarrow$ mean body sizes in the lower hole lag behind those in the upper hole \\
\hline \multirow[t]{2}{*}{$\begin{array}{l}\text { Number of individuals } \\
\text { of Prionocyphon } \\
\text { serricornis }\end{array}$} & $\begin{array}{l}\text { Significant } \\
\text { periodicity }\end{array}$ & $\begin{array}{c}\text { - for smaller time units (lag } 1 \text { ), positive changes in the lower hole are associated } \\
\text { with positive changes in the upper hole } \\
\text { - for larger time units (lag 4), positive changes in the lower hole are associated } \\
\text { with negative changes in the upper hole and vice versa }\end{array}$ \\
\hline & $\begin{array}{l}\rightarrow \text { stronger periodicity } \\
\text { in the upper hole }\end{array}$ & $\rightarrow$ abundances in the upper hole lag behind those in the lower hole \\
\hline \multirow[t]{2}{*}{$\begin{array}{l}\text { Mean body length } \\
\text { of Prionocyphon } \\
\text { serricornis }\end{array}$} & $\begin{array}{l}\text { Significant } \\
\text { periodicity }\end{array}$ & $\begin{array}{c}\text { - for smaller time units (lags } 3,5 \text { and } 6 \text { ), negative changes in the lower hole } \\
\text { are associated with negative changes in the upper hole } \\
\text { - for larger time units (lag 8), negative changes in the lower hole are associated } \\
\text { with positive changes in the upper hole and vice versa }\end{array}$ \\
\hline & $\begin{array}{c}\rightarrow \text { stronger periodicity } \\
\text { in the lower hole }\end{array}$ & $\rightarrow$ mean body sizes in the upper hole lag behind those in the lower hole \\
\hline
\end{tabular}

observed frequently in the tree holes during wet periods (Fig. S4-3).

The phenology of insect communities in tree holes varied between years and between the upper and lower canopy (Fig. 5). Surprisingly, the number of individuals in the holes at both heights peaked in winter in the first two years, but in summer in the third year. The partly synchronous and partly asynchronous temporal development of abundances in the upper and lower holes was confirmed by the partial autocorrelation analyses (Table 1, Fig. S3-4). Overall, the communities in the upper hole seemed to lag behind those in the lower hole (Table 1, Figs 5 \& S3-4). 


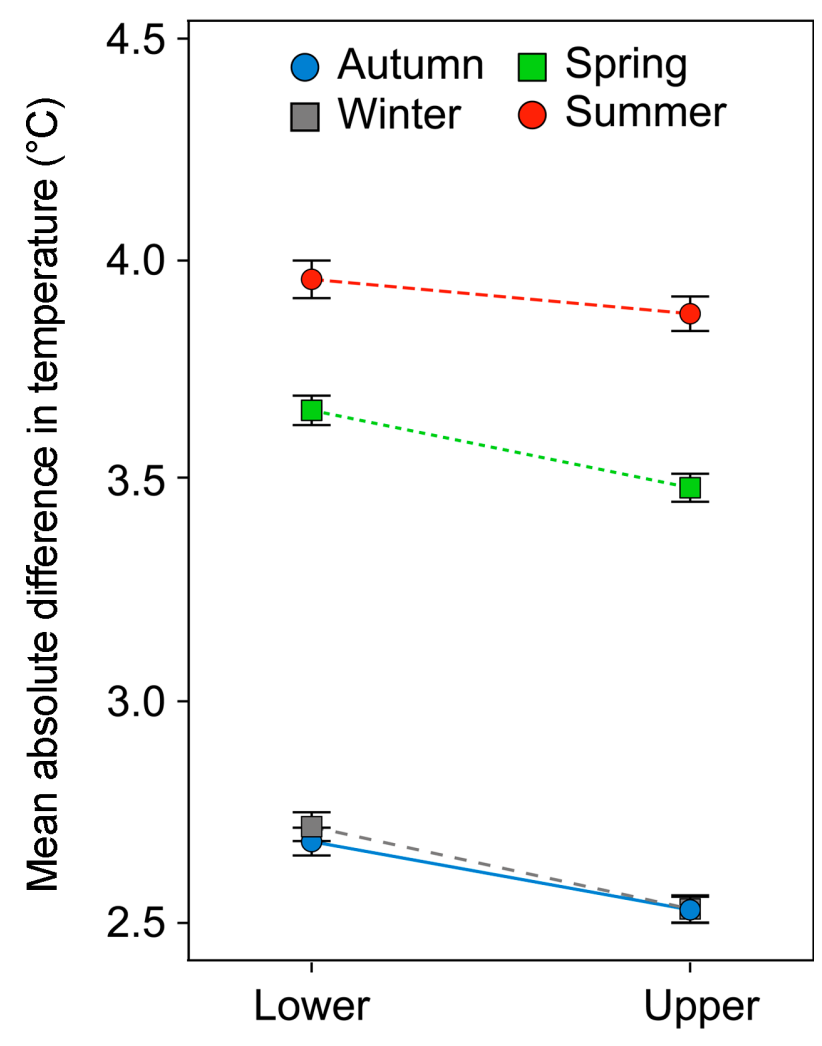

Tree hole

Fig. 2. Mean absolute difference ( \pm SE) between water and air temperature across all measurements per season in the the upper and lower tree holes in autumn, winter, spring and summer. Air temperature was measured at $2 \mathrm{~m}$ above ground at a nearby weather station.

Insect biomass in the lower canopy also peaked in winter in the first two years, but in autumn in the third year. In contrast, insect biomass in the upper canopy was overall lower than in the lower canopy and showed only one conspicuous peak in autumn in the second year. The partly synchronous temporal development of abundance in the upper and lower holes was confirmed by the partial autocorrelation analyses (Table 1, Fig. S3-5). Overall, the communities in the upper hole seemed to lag behind those in the lower hole (Table 1, Figs 5 \& S3-5).

The highest species richness in the lower canopy occurred in winter in the first, in winter/spring in the second and in winter/summer in the third year. In the upper canopy, most species were found in winter and summer in the second year. Partial autocorrelation analyses supported the partly asynchronous temporal development of species richness in the upper and lower holes (Table 1, Fig. S3-5). Overall, the communities in the upper hole seemed to lag behind those in the lower hole at some point and vice versa at other points (Table 1, Figs $5 \&$ S3-5).

Regarding the two most abundant species, M. cavicola reached a maximum of 16 individuals per $15 \mathrm{ml}$ in the lower tree hole and 14 in the upper hole. The maximum abundance of $P$. serricornis per sampling event was 7 individuals in the lower and 3 individuals in the upper hole. Both species showed a similar phenology in the lower and upper tree holes, but the time of maximum abundance differed among years. The evidence for periodicity in the abundance and body length of $M$. cavicola was stronger in the upper hole than in the lower hole. Interestingly, the abundance in the upper hole lagged behind that in the lower hole, while a different pattern was recorded for body size (Table 1, Figs 6, S3-6 \& S3-7). The continuous occurrence of late instar larvae of $M$. cavicola over several months indicates repeated colonization events. The evidence for periodicity in the abundance of $P$. serricornis was stronger in the upper than in the lower hole, and a similar pattern was recorded for body size (Table 1, Figs 6, S3-8 \& S3-9). The abundances and mean body sizes in the upper hole lagged behind those recorded in the lower hole (Table 1, Figs S3-8 \& S3-9). The phenology of other species also seemed to differ among years (Fig. S2-1), but a more detailed analysis was not possible because of the low overall abundance. Interestingly, the phenology of Dasyhelea sp. seemed to follow an opposite pattern to that recorded for M. cavicola.

\section{DISCUSSION}

The present study is, to my knowledge, the first three year study of the phenology of dendrotelmata-inhabiting insects in natural tree holes in Central Europe. This study is based on data from two tree holes in one tree, and thus, the results cannot be generalized. However, some interesting patterns were recorded that should encourage future research at larger spatial scales. First, the periodicity at the community and population levels in both tree holes were not strongly linked to season, leading to different patterns in different years. It is likely that the variation in temperature and tree-hole-filling precipitation between years, leading to acyclic drying out of tree holes, determines the periodicity of communities of insect larvae in dendrotelmata. Second, the lower species richness in the upper tree hole might indicate harsher conditions high in the canopy. It is likely that tree holes in the upper canopy are less well buffered against changes in air temperature than those in the lower canopy and thus are more likely to dry out.

\section{Abiotic temporal patterns}

The volume and the $\mathrm{pH}$ and oxygen saturation of the water in the tree holes studied were within the range of values recorded in a large-scale study on tree holes published by Gossner et al. (2016), except for the extremely high value of oxygen saturation recorded in the upper hole (42\%) (Fig. S1-2). The range in water temperature, from freezing to more than $25^{\circ} \mathrm{C}$, is within the range previously reported (von Brandt, 1934; Rohnert, 1951; Schmidl et al., 2008; Gossner et al., 2016), although most of these studies did not include the winter season. That the water temperature in winter did not go below $-3^{\circ} \mathrm{C}$ is in accordance with the findings of Rohnert (1951). Although there is a clear seasonal pattern in water temperature in the waterfilled tree holes studied, which followed changes in air temperature, water temperature was mainly determined by the height above ground of tree holes and by irregular precipitation that fills the tree holes, mainly via stem flow. 


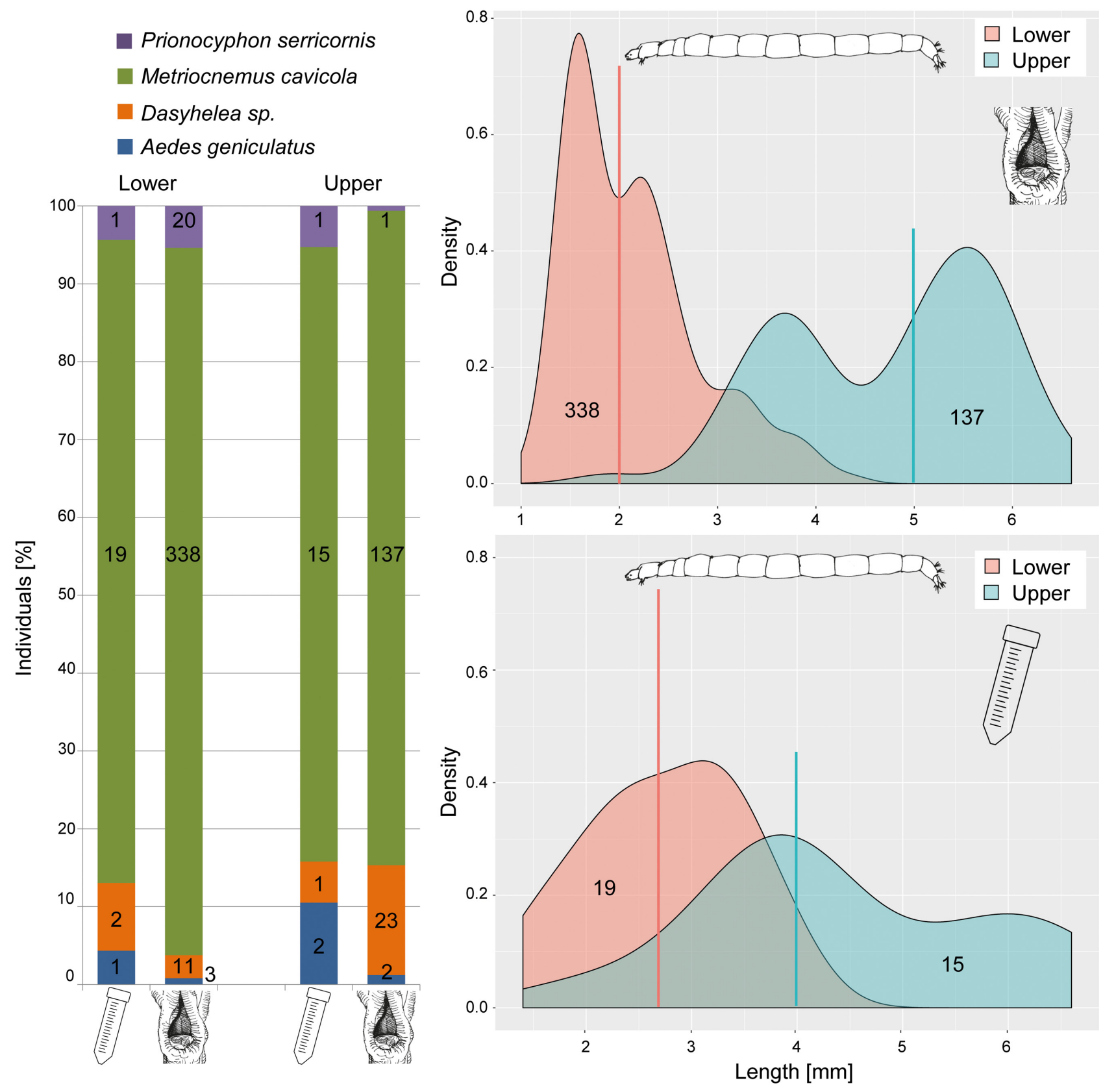

Fig. 3. Comparison of the communities in the $15 \mathrm{ml}$ samples (Icon Falcon tube) and complete harvest (Icon tree hole) collected in June 2017 , one year after termination of the study. Left: Community composition in the lower and upper tree holes; numbers refer to the number of individuals. Right: Size distribution of Metriocnemus cavicola in the complete harvest (top) and the $15 \mathrm{ml}$ samples from the lower and upper holes (bottom). The vertical lines indicate the median size. The Falcon tube icon was created by Julie Ko from Noun Project.

The temperature of the water in the tree holes is buffered against air temperature (see also von Brandt, 1934; Mayer, 1938; Rohnert, 1951), but the extent of such buffering in forests most likely decreases with height above the ground and also depends on exposure. Independent of height and exposure, however, tree holes seem to dry out regularly, particularly in late winter/early spring before bud burst, and completely freeze in winter, but the frequency of these events increases with height. Freezing of water in tree holes in winter is also reported in early studies (Rohnert, 1951).

\section{Sampling temporal dynamics of tree hole communities}

To study temporal dynamics of tree hole communities, sampling was conducted bimonthly by collecting a $15 \mathrm{ml}$ sample of water from each hole. This was done because (1) species identification and measurements in the field were not feasible and thus sampling of complete tree holes, as proposed by Yanoviak \& Fincke (2005), was not practical; and (2) insect dynamics in tree holes vary enormously between habitats (Kitching, 2000), and thus sampling different tree holes at different points in time was not a suitable solution. It is likely that the sampling method used in the 


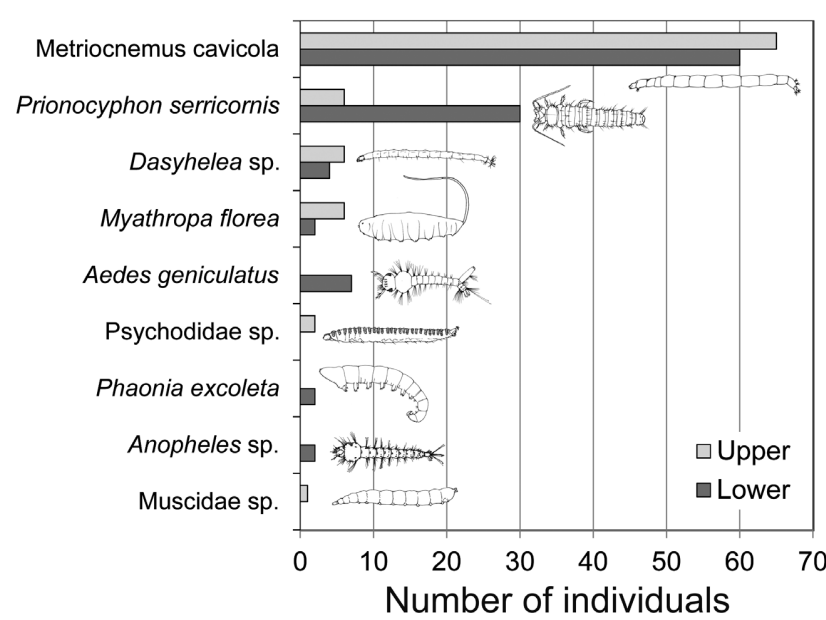

Fig. 4. Overview of the nine species that were recorded in one or other, or both, of the two tree holes studied (Lower $10.2 \mathrm{~m}$ and Upper $20.2 \mathrm{~m}$ above ground level) between 2013 and 2016 .

present study is suitable and practical for analyzing temporal patterns, provided that tree holes are not too small, i.e. have a volume of at least one liter, because (1) all species in the complete harvest collected during the additional assessment in 2017 were detected in the $15 \mathrm{ml}$ samples; (2) all of the more abundant species and a few of the less abundant species that were found in a previous large-scale study on insect larvae in water-filled tree holes in Central European beech forests (Gossner et al., 2016) were found in the samples collected in the present study; (3) the difference in the size distribution of the most abundant species, M. cavicola, between the lower and upper tree holes in the complete harvest collected during the additional assessment in 2017 was consistent with the difference observed in the $15 \mathrm{ml}$ samples; and (4) results showed a clear periodicity in the communities and in the phenology of particular species.

\section{Seasonality in the insect communities}

There was no clear seasonality in the communities of larvae in tree holes, which is in line with observations in moist deciduous woodlands in Great Britain (Kitching, 1971) and in subtropical forests in Queensland, Australia (Kitching, 1983, 1987; Kitching \& Beaver, 1990). Kitching (2000) proposes that the lack of seasonality in regions with pronounced seasons might be due to the slow development of saprophagous insect larvae, which is associated with the low nutritional value of their food. He assumes that seasonality occurs only in locations where holes dry out completely for long periods of time. In contrast, there was a clear periodicity in the communities studied, which was independent of season, although the tree holes studied were full of water most of the time during this study. This finding tends to indicate that the unpredictable occurrence of drying out might result in non-seasonal patterns. Culicidae and Prionocyphon larvae might in general have a low resistance to drought (Srivastava, 2005) and therefore exclusively occur in tree holes in the lower canopy that are less likely to dry out. Species are well adapted to these unpredictable events as their less sensitive stages, such as eggs or pupae, can survive such extreme periods.
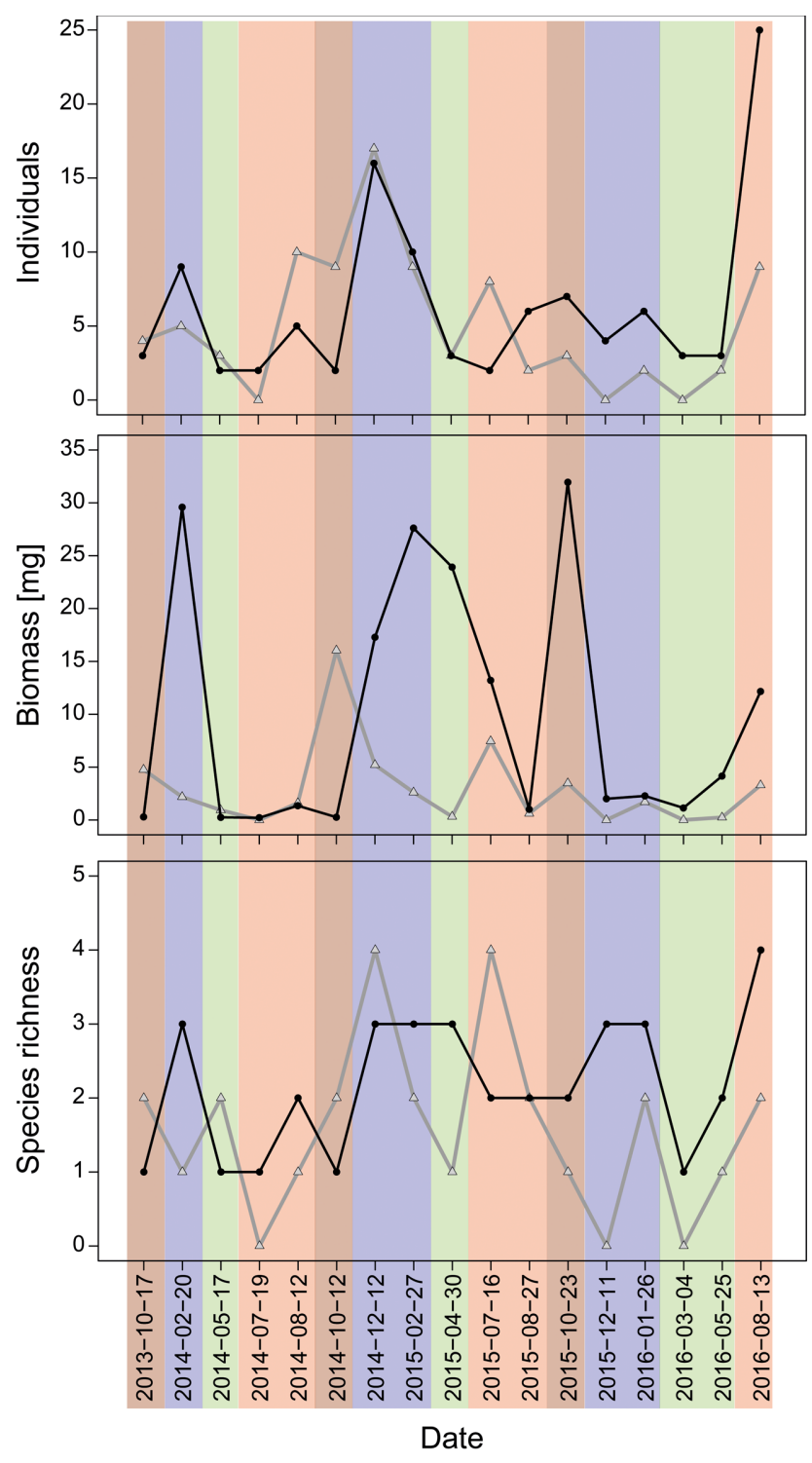

Fig. 5. The numbers, biomass and species richness of the insects recorded in the samples collected from the tree holes at $10.2 \mathrm{~m}$ (black symbol and line) and $20.2 \mathrm{~m}$ (grey symbol and line) above the ground on each date sampled between 2013 and 2016. Colours indicate the season (brown: autumn, blue: winter, green: spring, red: summer).

Some species of the families Chironomidae and Ceratopogonidae, as well as M. florea and P. serricornis, can survive as larvae, even when the water in a tree hole is completely frozen, as observed in the present study (see also von Brandt, 1934; Rohnert, 1951). Larvae of Scirtidae often overwinter in water above the ice layer and pupate in spring (Barrera, 1996; own observations). Some species might, however, be more sensitive in particular stages; for example, late larval stages of $M$. florea did not survive freezing for four weeks in the upper tree hole in one year. This is also reported by Rotheray (2013) for different species of Syrphidae. Although Rohnert (1951) proposes that larvae might be able to survive freezing conditions lasting 3-4 weeks, the population is strongly reduced in winter, in particular when conditions are extremely severe, like in the above-mentioned year in this study. In contrast, Culicidae 

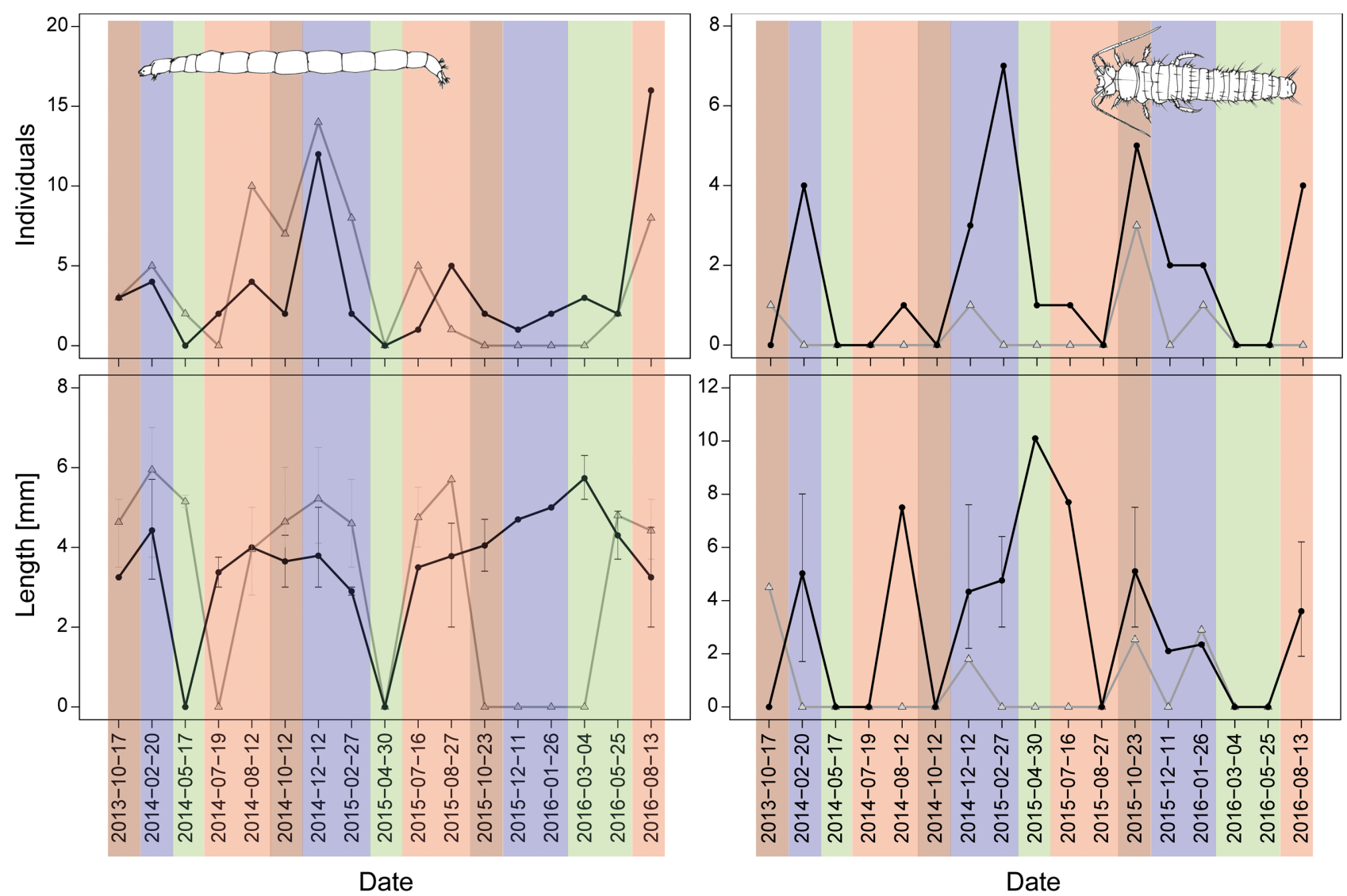

Fig. 6. Total number of individuals and average body length (mean, Min-Max) of Metriocnemus cavicola (Diptera: Chironomidae; left) and Prionocyphon serricornis (Coleoptera: Scirtidae; right) in the $15 \mathrm{ml}$ samples of water collected from the tree holes at $10.2 \mathrm{~m}$ (black symbol and line) and $20.2 \mathrm{~m}$ (grey symbol and line) above the ground on each date sampled between 2013 and 2016. Colours indicate the season (brown: autumn, blue: winter, green: spring, red: summer).

have very low frost resistance and overwinter in either the egg or adult stage. Thus, species-specific traits influence their phenology.

Interestingly, the communities in the upper tree hole lagged behind those in the lower tree hole in the present study. This might indicate that the insects first colonize those microhabitats that are less likely to dry out. In contrast, species that are less drought sensitive, such as Dashylea sp., M. cavicola and M. florea (Srivastava, 2005; Dominiak, 2012), might be avoiding competition by colonizing tree holes in the upper canopy.

\section{Seasonality of the most abundant species}

M. cavicola and P. serricornis were by far the most abundant species in the present study. Both species were also among the most abundant species in previous studies of communities in water-filled tree holes in Central European forests (Kitching, 1971; Schmidl et al., 2008; Gossner et al., 2016). In the present study, both species showed a clear periodicity that was stronger in the upper canopy, most likely due to the more frequent drying out of the upper tree hole. For both species, Kitching (1971, 1972a, 2000) also found a clear seasonal pattern during a one-year study in Great Britain. In agreement with the studies of Kitching, $M$. cavicola occurred year round in the present study, and the simultaneous occurrence of different larval stages indicates multiple colonization events. However, the high numbers in summer reported by Kitching (2000) were not recorded in the present study. Depending on the year, abundances and average body sizes peaked in summer or winter, indicating a non-seasonal periodicity. Interestingly, Dashylea sp., which occupy an ecological niche similar to that of M. cavicola, peaked in abundance at times when the abundance of M. cavicola was low. Moreover, species that are less drought sensitive occurred mainly in the upper tree hole and might thereby avoid competition. These findings might indicate co-evolved temporal competitive exclusion, as proposed by Kitching $(1969,2000)$ and Barrera (1996). More comprehensive studies on the phenology of these species, including exclusion experiments, are necessary to clarify whether competitive exclusion is a driver of tree hole community dynamics.

Abundance and body size of $P$. serricornis (drought sensitive) in the upper hole lagged behind the values recorded for this species in the lower hole. For M. cavicola (drought resistant), this pattern was only observed for abundance, while body size in the lower hole lagged behind that in the upper hole. This result probably indicates that both species colonize holes in the lower canopy first, most likely a consequence of their searching for the most suitable habitats. The probability of finding suitable microhabitats decreases with height in trees because of decreasing availability of their microhabitat. In the study of Gossner et al. (2016), 
one to three times more tree holes occurred in the canopy ( $>2 \mathrm{~m}$ height) than near the ground, but the average height was $4 \mathrm{~m}$ in both of the regions studied. However, $M$. cavicola seems to mainly colonize tree holes high in the canopy (greater overall abundance was recorded in the upper tree hole) where they develop faster, most likely due to the higher water temperatures in these more exposed holes. Therefore, the body size of this species in the lower tree hole lagged behind that recorded in upper tree hole.

\section{CONCLUSIONS}

This three year study on the phenology of insect larvae in water-filled tree holes revealed some interesting patterns that should followed up in the future by studies at larger spatial scales, including experimental work. Based on the results presented and those of previous studies, the following hypotheses are proposed and should be tested in the future: (1) the periodicity of insect communities in waterfilled tree holes in Central European forests is independent of season and driven by irregular drying out of tree holes; (2) within canopies, species richness in water-filled tree holes decreases with height above ground due to the harsher conditions prevailing in the upper canopy; (3) differences in microclimate result in different temporal dynamics in the lower and upper canopy; and (4) competitive exclusion is an important structuring mechanism of the communities of insect larvae inhabiting water-filled tree holes.

ACKNOWLEDGMENTS. I am grateful to the forestry enterprise at Freising for supporting this study in the forest district "Schlemmerholz", to S. Mathis and A. Knecht for helping sort the samples of the additional assessment in 2017, three anonymous reviewers for their valuable comments and M. Dawes for linguistic editing.

\section{REFERENCES}

BARRERA R. 1996: Species concurrence and the structure of a community of aquatic insects in tree holes. - J. Vector Ecol. 21: 66-80.

Bradshaw W.E. \& Holzapfel C.M. 1984: Seasonal development of tree-hole mosquitoes (Diptera: Culicidae) and chaoborids in relation to weather and predation. - J. Med. Entomol. 21: 366-378.

Carlisle A., Brown A. \& White E. 1966: The organic matter and nutrient elements in the precipitation beneath a sessile oak (Quercus petraea) canopy. - J. Ecol. 54: 87-98.

CARPENTER S.R. 1982: Stemflow chemistry: Effects on population dynamics of detritivorous mosquitoes in tree-hole ecosystems. - Oecologia 53: 1-6.

CARPENTER S.R. 1983: Resource limitation of larval treehole mosquitoes subsisting on beech detritus. - Ecology 64: 219-223.

Cranston P.S. 1982: A key to the larvae of the British Orthocladiinae (Chironomidae). - Sci. Publ. Freshw. Biol. Assoc. 45: $1-152$.

Cranston P.S. \& Judd D.D. 1987: Metriocnemus (Diptera: Chironomidae): an ecological survey and description of a new species. - J. N. Y. Entomol. Soc. 95: 534-546.

Devetter M. 2004: Invertebrate fauna of treeholes in relation to some habitat conditions in southern Bohemia (Czech Republic). — Acta Soc. Zool. Bohem. 68: 161-168.
Dixon T.J. 1960: Key to and descriptions of the third instar larvae of some species of Syrphidae (Diptera) occurring in Britain. Trans. R. Entomol. Soc. Lond. 112: 345-379.

Dominiak P. 2012: Biting midges of the genus Dasyhelea Kieffer (Diptera: Ceratopogonidae) in Poland. - Pol. J. Entomol. 81: 211.

Eaton J.S., Likens G.E. \& Bormann F.H. 1973: Throughfall and stemflow chemistry in a northern hardwood forest. - J. Ecol. 61: 495-508.

Fish D. \& CARPenter S.R. 1982: Leaf litter and larval mosquito dynamics in tree-hole ecosystems. - Ecology 63: 283-288.

Gossner M.M., Lade P., Rohland A., Sichardt N., Kahl T., Bauhus J., Weisser W.W. \& Petermann J.S. 2016: Effects of management on aquatic tree-hole communities in temperate forests are mediated by detritus amount and water chemistry. —J. Anim. Ecol. 85: 213-226.

GrEen D. 1990: A study of the faunas of water-filled tree-holes and memorial vases. - Vasculum 75: 27-39.

Hartley J.C. 1961: A taxonomic account of the larvae of some British Syrphidae. - Proc. Zool. Soc. Lond. 136: 505-573.

Kitching R.L. 1969: The Fauna of Tree-Holes in Relation to Environmental Factors. PhD Thesis, University of Oxford, Oxford.

Kitching R.L. 1971: An ecological study of water-filled treeholes and their position in the woodland ecosystem. - J. Anim. Ecol. 40: 281-302.

KITCHING R. 1972a: Population studies of the immature stages of the tree-hole midge Metriocnemus martinii Thienemann (Diptera: Chironomidae). - J. Anim. Ecol. 41: 53-62.

Kitching R.L. 1972b: The immature stages of Dasyhelea dufouri Laboulbene (Diptera: Ceratopogonidae) in water-filled treeholes. - J. Entomol. (A) 47: 109-114.

Kitching R.L. 1983: Community structure in water-filled treeholes in Europe and Australia-comparisons and speculations. In Frank J.H. \& Lounibos L.P. (eds): Phytotelmata: Terrestrial Plants as Hosts for Aquatic Insect Communities. Plexus, Medford, NJ, pp. 205-222.

KITCHING R.L. 1987: Spatial and temporal variation in food webs in water-filled treeholes. - Oikos 48: 280-288.

Kitching R.L. 2000: Food Webs and Container Habitats: The Natural History and Ecology of Phytotelmata. Cambridge University Press, Cambridge, xiii +429 pp.

Kitching R.L. \& Beaver R.A. 1990: Patchiness and Community Structure. Oxford University Press, Oxford, pp. 147-176.

Klausnitzer B. 1996: Die Larven der Käfer Mitteleuropas: L6: Polyphaga: Teil 5. Gustav Fischer, Jena, 310 pp.

LindegaARD C. 1997: Diptera Chironomidae, non-biting midges. In Nilsson A. (ed.): Aquatic Insects of North Europe 2. Apollo Books, Stenstrup, pp. 265-294.

MAYER K. 1938: Zur Kenntnis der Buchenhöhlenfauna. - Arch. Hydrobiol 33: 388-400.

MERCER D.R. 1993: Effect of tannic acid concentration on development of the western treehole mosquito, Aedes sierrensis (Diptera: Culicidae). - J. Chem. Ecol. 19: 1119-1127.

MoHrig W. 1969: Die Culiciden Deutschlands: Untersuchungen zur Taxonomie, Biologie und Ökologie der einheimischen Stechmücken. - Parasitol. Schriflenr. 18: 1-260.

NiLsson A.N. 1996: Aquatic Insects of North Europe: A Taxonomic Handbook. Vol. 1: Ephemeroptera, Plecoptera, Heteroptera, Neuroptera, Megaloptera, Coleoptera, Trichoptera, Lepidoptera. Apollo Books, Stenstrup, 274 pp.

NiLsson A.N. 1997: Aquatic Insects of North Europe: A Taxonomic Handbook. Vol. 2: Odonata, Diptera. Apollo Books, Stenstrup, $440 \mathrm{pp}$. 
Pankratova V.Y. 1970: Key to the larvae of the genera of the subfamily Orthocladiinae from larvae and pupae of midges of the sub-family Orthocladiinae of the fauna of the USSR. - FBA Transl. (N.S.) 54: 51-55.

PARADISE C.J. 2004: Relationship of water and leaf litter variability to insects inhabiting treeholes. - J. North. Am. Benthol. Soc. 23: 793-805.

PARAdISE C.J. \& Dunson W.A. 1998: Relationship of atmospheric deposition to the water chemistry and biota of treehole habitats. - Environ. Toxicol. Chem. 17: 362-368.

Paradise C.J., Blue J.D., Burkhart J.Q., Goldberg J., Harshaw L., Hawkins K.D., Kegan B., Krentz T., Smith L. \& VillalpanDO S. 2008: Local and regional factors influence the structure of treehole metacommunities. - BMC Ecol. 8: 22, 16 pp.

Petermann J.S., Farjalla V.F., Jocque M., Kratina P., MacDonald A.A.M., Marino N.A.C., de Omena P.M., Piccoli G.C.O., Richardson B.A., Richardson M.J., Romero G.Q., Videla M. \& SRIVASTAVA D.S. 2015: Dominant predators mediate the impact of habitat size on trophic structure in bromeliad invertebrate communities. - Ecology 96: 428-439.

Petermann J.S., Rohland A., Sichardt N., Lade P., Guidetti B., Weisser W.W. \& Gossner M.M. 2016: Forest management intensity affects aquatic communities in artificial tree holes. PLOS ONE 11: e 0155549, 22 pp.

Ptatscheck C. \& Traunspurger W. 2015: Meio- and macrofaunal communities in artificial water-filled tree holes: effects of seasonality, physical and chemical parameters, and availability of food resources. - PLOS ONE 10: e133447, 16 pp.

RoHNERT U. 1951: Wassererfüllte Baumhöhlen und ihre Besiedlung: ein Beitrag zur Fauna dendrolimnetica. - Arch. Hydrobiol. 44: 473-516.

Rotheray G.E. 1993: Colour guide to hoverfly larvae (Diptera, Syrphidae) in Britain and Europe. - Dipterists Digest 9: $1-155$.

RotherAY E.L. 2013: Differences in ecomorphology and microhabitat use of four saproxylic larvae (Diptera, Syrphidae) in Scots pine stump rot holes. - Ecol. Entomol. 38: 219-229.

Rotheray E.L., Goulson D. \& Bussière L.F. 2016: Growth, development, and life-history strategies in an unpredictable environment: case study of a rare hoverfly Blera fallax (Diptera, Syrphidae). - Ecol. Entomol. 41: 85-95.

RozkoŠnÝ R. \& GREGOR F. 2004: Insecta: Diptera: Muscidae. Elsevier, München, $111 \mathrm{pp}$.

Schmidl J., Sulzer P. \& Kitching R.L. 2008: The insect assemblage in water filled tree-holes in a European temperate deciduous forest: community composition reflects structural, trophic and physicochemical factors. - Hydrobiologia 598: 285-303.

Sinsko M.J. \& Craig G.B. 1979: Dynamics of an isolated population of Aedes triseriatus (Diptera: Culicidae). I. Population size. - J. Med. Entomol. 15: 89-98.

Smith L.M., Blue J., Carlson J., Metz G., Haywood J., Bush D. \& PARADISE C.J. 2009: Density-dependent predation of a dominant species does not facilitate increased diversity in treeholes. _Open Ecol. J. 2: 91-99.

Sмоск L.A. 1980: Relationships between body size and biomass of aquatic insects. - Freshw. Biol. 10: 375-383.
SoтA T. 1996: Effects of capacity on resource input and the aquatic metazoan community structure in phytotelmata. - Res. Popul. Ecol. 38: 65-73.

SRIVASTAVA D.S. 2005: Do local processes scale to global patterns? The role of drought and the species pool in determining treehole insect diversity. - Oecologia 145: 205-215.

Srivastava D.S., Kolasa J., Bengtsson J., Gonzalez A., Lawler S.P., Miller T.E., Munguia P., Romanuk T., Schneider D.C. \& TRZCINSKI M.K. 2004: Are natural microcosms useful model systems for ecology? - Trends Ecol. Evol. 19: 379-384.

Srivastava D.S., Trzcinski M.K., Richardson B.A. \& Gilbert B. 2008: Why are predators more sensitive to habitat size than their prey? Insights from bromeliad insect food webs. - Am. Nat. 172: 761-771.

STEHR F.W. 1987: Immature Insects. Vol. 1. Kendall/Hunt, Dubuque, $754 \mathrm{pp}$.

Stresemann E., Klausnitzer B., Hannemann H.-J. \& Senglaub K. 2005: Stresemann-Exkursionsfauna von Deutschland, Band 2: Wirbellose: Insekten. Springer Spektrum, $966 \mathrm{pp}$.

Theinemann A. 1934: Der Tierwelt der tropischen Planzengewässer. - Arch. Hydrobiol. (Suppl.) 13: 1-91.

Utrio P. 1976: Identification key to Finnish mosquito larvae (Diptera, Culicidae). - Ann. Agric. Fenn. 15: 128-136.

VARGA L. 1928: Ein interessanter Biotop der Biocönose von Wasserorganismen. - Biol. Zentralbl. 48: 143-162.

Venables W. \& Ripley B. 2002. Modern Applied Statistics Using $S$. Springer, New York, $498 \mathrm{pp}$.

VON BRANDT A. 1934: Untersuchungen in Baumhöhlengewässern auf Fagus sylvatica. - Arch. Hydrobiol. 27: 546-563.

Woodward D., Colwell A. \& Anderson N. 1988: The aquatic insect communities of tree holes in northern California oak woodlands. - Bull. Soc. Vector Ecol. 13: 221-234.

YANOVIAK S.P. 2001: Predation, resource availability, and community structure in Neotropical water-filled tree holes. - Oecologia 126: 125-133.

YANOviaK S.P. \& FincKe O.M. 2005: Sampling methods for water-filled tree holes and their artificial analogues. In Leather S.R. (ed.): Insect Sampling in Forest Ecosystems. Blackwell, Oxford, pp. 168-185

YanoviaK S.P., Paredes J.E.R., Lounibos L.P. \& Weaver S.C. 2006: Deforestation alters phytotelm habitat availability and mosquito production in the Peruvian Amazon. - Ecol. Appl. 16: $1854-1864$.

Yee D.A. \& Juliano S.A. 2006: Consequences of detritus type in an aquatic microsystem: Effects on water quality, micro-organisms and performance of the dominant consumer. - Freshw. Biol. 51: 448-459.

Received April 24, 2018; revised and accepted September 6, 2018 Published online October 2, 2018

Supplementary file: http://www.eje.cz/2018/052/S01.pdf. Supplement S1: Details of the stand and tree studied. Supplement S2: Periodicity in the numbers of rare species. Supplement S3: Details of time series analyses. Supplement S4: Data on the species of insects collected. Supplement S5: Raw species data. 